\title{
ANTROPOMETRIC AND MOTOR ABILITIES DEVELOPMENT AMONG 10-12 YEARS AGED PUPILS IN ALBANIA
}

\author{
Rovena Elmazi \\ Sports University of Tirana, Faculty of Physical Activity and Recreation
}

\begin{abstract}
One of the major problems of Albania in this day and age is sedentary life characterizing children, a phenomenon which is observed in this age group in most parts of the world. However, the factors leading to this phenomenon in Albania seem to be of a different nature, as compared to those responsible in most developed countries. In general, a number of factors, such as lack of sports facilities, low economic development of the country and other social factors hinder the participation in physical activity and sport of young children living in rural and urban areas in Albania. While in urban areas technological advance also amounts to some extent to fewer and fewer children engaging in physical activities and sports in urban areas. The study aimed to assess anthropometric and physical skills development of students aged 10-12 years living in rural and urban areas of Albania, and further examine the indicators obtained in order to study how these two groups of children compare to each other. The data gathered through this study are indispensable in revealing the level of obesity, physical preparation and identifying talented athletes. 641 students coming from the primary and secondary school systems were subjected to standard anthropometric measurements (weight/height/BMI) and standard physical fitness tests (push-up, high jump, long jump, horizontal stretch, 30m dash, shuttle run $112 \mathrm{~m}$ ). Based on BMI standards for children of this age group, it can be observed that children living in rural areas demonstrate a growth in body mass which is within the optimal range level for both boys and girls. Even the physical fitness indicators tested speak for a bigger development of children coming from rural areas as compared to their peers living in the city.
\end{abstract}

Key words: anthropometric parameters, talent identification, motor skills, pupils

\section{INTRODUCTION}

Doing sports activities, in addition to fresh air, sun and nutrition, is of special importance in the healthy raising of children. Sport plays an extraordinary role in the development of children. It is considered a key factor for an optimal physical and mental health of children (Denkere, Andersen, 2008). It not only serves for the protection and boosting of children's health so that they have a strong body, perform graceful movements, but also to decrease prevalence of overweight and obesity in children who are unlikely to become so in adulthood. The capacity of performing physical activity is named physical fitness or motor fitness, albeit these terms are difficult to define (Gallahue, 1982). The main indicators of physical development depend on factors which include external environment and socio-economic factors. These factors are constantly changing in our country and consequently, physical development of children is subject to changes from one group-age to another.

Motor abilities represent an integrated outcome of most bodily functions involved in physical activity and can be used to assess the effectiveness of physi- cal education, as well as measure the health-related fitness of schoolchildren, provided they are reliably measured by standardized tests, such as EUROFIT test battery (Adam, Klissouras, Ravazzolo, Renson, Tuxworth, 1988), which has been widely used with children and adolescents (Tomkinson, Olds, Borms 2007). Simultaneous assessment of anthropometric parameters and motor abilities will provide more accurate information on the developmental process of children; however, it is not well known whether a relationship actually exists between motor abilities and anthropometric parameters in children or between different motor ability evaluation tests.

\section{METHODOLOGY}

The aim of this investigation was to evaluate physical fitness and differences observed in children living in different areas and coming from different economic situations and show how important recreation activity is for their health land physical preparation.

641 students between the ages of 10-12 coming from both rural and urban areas participated in the study, of whom 298 girls and 343 boys. 
Out of the nine tests in the "Eurofit-Test" battery, for the purpose of the study, only six were used; flexibility, speed, agility, endurance and strength. "Eurofit-Test" test battery is a standardized test, designed by the Council of Europe for school children and has been used in many European schools since 1988. It is designed in a manner that enables testing to be completed within $35-40$ minutes by using very simple equipment. The parameters measured for the purpose of this study were: 1 . Height (L), 2. Weight (W), 3. Body Mass Index (BMI), 4. SitUps -Abdominal (SUP), 5. Sit and Reach (SAR), 6. Standing Broad Jump (SBJ).

In addition, to carry out the study other alternative tests were used: 7. Vertical jump (VJ), 8. Push up (PU), 9. 30-Meter Speed Test (30mST), 10. Shuttle Run 112 meters (SHR). All these tests included in the study were chosen to evaluate anthropometrical parameters, obesity levels, physical preparation and to identify talented athletes.

\section{A. Equipment used in measuring}

To measure the height of the students a Harpenden portable Stadiometer with $1 \mathrm{~cm}$ sensitivity was used. Weight was measured and rounded to the nearest $0.1 \mathrm{~kg}$ using an electronic scale (TANITA Segmental Body Composition BC-545N). Body Mass Index was calculated as $\mathrm{kg} / \mathrm{m}$. In Standing Broad Jump (SBJ) and Vertical Jumping Tests an iPhone application was used to determine the heights of the students' jumps. For the 30-Meter Speed Test $(30 \mathrm{mST})$ with a standing position at the start and the 112 Meter-Shuttle Run (SHR) time was measured with a stop-watch.

\section{B. Data Analysis}

SPSS 22 Program was used in calculating the average, standard deviation and percentage values of physical and motor data collected for the study. BMI data obtained from the study were compared to norm values provided by the American Public Health Agency to identify underweight, normal weight, overweight or obese subjects.

According to the results, some substantial differences $(p<0,05)$ between the players with respect to height $(\mathrm{cm})$, weight $(\mathrm{kg})$, flexibility $(\mathrm{cm})$, standing broad jump and vertical jump $(\mathrm{cm}), 112$-metershuttle run test $(\mathrm{ml} / \mathrm{kg} / \mathrm{min}), 30$-meter-sprint were observed, while no significant differences $(p>0,05)$ have been found with respect to parameters such as BMI (\%), and number of sit-ups and push-ups correctly executed in $30 \mathrm{~s}$.

\section{RESULTS}

In the tables below are the BMI indicators of Primary and Secondary School students aged 10-12 in both rural and urban areas and data obtained from the Eurofit test battery.

Table 1. Body Mass Index by age groups \& gender in urban areas of Albania

\begin{tabular}{|c|c|c|c|c|c|c|c|c|c|}
\hline \multirow{3}{*}{ Age } & \multicolumn{9}{|c|}{ URBAN AREAS } \\
\cline { 2 - 11 } & \multicolumn{3}{|c|}{ BOY } & \multicolumn{3}{c|}{ GIRL } & \multicolumn{3}{c|}{ TOTAL } \\
\cline { 2 - 10 } & $\begin{array}{c}\text { UNDER } \\
\text { WEIGHT }\end{array}$ & NORMAL & OBESE & $\begin{array}{c}\text { UNDER } \\
\text { WEIGHT }\end{array}$ & NORMAL & OBESE & $\begin{array}{c}\text { UNDER } \\
\text { WEIGHT }\end{array}$ & NORMAL & OBESE \\
\cline { 2 - 10 } & $\mathbf{R o w}$ & Row & Row & Row & Row & Row & Row & Row & Row \\
& $\mathbf{N} \%$ & $\mathbf{N} \%$ & $\mathbf{N} \%$ & $\mathbf{N} \%$ & $\mathbf{N} \%$ & $\mathbf{N} \%$ & $\mathbf{N} \%$ & $\mathbf{N} \%$ & $\mathbf{N} \%$ \\
\hline 10.00 & $73.3 \%$ & $20.0 \%$ & $6.7 \%$ & $58.5 \%$ & $32.3 \%$ & $9.2 \%$ & $65.6 \%$ & $26.4 \%$ & $8.0 \%$ \\
\hline 11.00 & $65.8 \%$ & $31.6 \%$ & $2.5 \%$ & $64.0 \%$ & $34.7 \%$ & $1.3 \%$ & $64.9 \%$ & $33.1 \%$ & $1.9 \%$ \\
\hline 12.00 & $48.7 \%$ & $46.2 \%$ & $5.1 \%$ & $81.8 \%$ & $18.2 \%$ & $0.0 \%$ & $60.7 \%$ & $36.1 \%$ & $3.3 \%$ \\
\hline Total & $\mathbf{6 4 . 6 \%}$ & $\mathbf{3 0 . 9} \%$ & $\mathbf{4 . 5 \%}$ & $\mathbf{6 4 . 2 \%}$ & $\mathbf{3 1 . 5 \%}$ & $\mathbf{4 . 3 \%}$ & $\mathbf{6 4 . 4 \%}$ & $\mathbf{3 1 . 2 \%}$ & $\mathbf{4 . 4 \%}$ \\
\hline
\end{tabular}

Table 2. Body Mass Index by age groups \& gender in rural areas of Albania

\begin{tabular}{|c|c|c|c|c|c|c|c|c|c|}
\hline \multirow{3}{*}{ Age } & \multicolumn{9}{|c|}{ RURAL AREAS } \\
\cline { 2 - 10 } & \multicolumn{3}{|c|}{ BOY } & \multicolumn{3}{c|}{ GIRL } & \multicolumn{3}{c|}{ TOTAL } \\
\cline { 2 - 10 } & UNDER & NORMAL & OBESE & $\begin{array}{c}\text { UNDER } \\
\text { WEIGHT }\end{array}$ & NORMAL & OBESE & $\begin{array}{c}\text { UNDER } \\
\text { WEIGHT }\end{array}$ & NORMAL & OBESE \\
\cline { 2 - 10 } & Row & Row & Row & Row & Row & Row & Row & Row & Row \\
& $\mathbf{N} \%$ & $\mathbf{N} \%$ & N \% & N \% & N \% & N \% & N \% & N \% & N \% \\
\hline 10.00 & $69.2 \%$ & $30.8 \%$ & $0.0 \%$ & $67.4 \%$ & $30.2 \%$ & $2.3 \%$ & $68.4 \%$ & $30.5 \%$ & $1.1 \%$ \\
\hline 11.00 & $61.5 \%$ & $36.9 \%$ & $1.5 \%$ & $74.5 \%$ & $25.5 \%$ & $0.0 \%$ & $67.2 \%$ & $31.9 \%$ & $.9 \%$ \\
\hline 12.00 & $70.8 \%$ & $27.1 \%$ & $2.1 \%$ & $76.2 \%$ & $19.0 \%$ & $4.8 \%$ & $73.3 \%$ & $23.3 \%$ & $3.3 \%$ \\
\hline Total & $\mathbf{6 6 . 7 \%}$ & $\mathbf{3 2 . 1 \%}$ & $\mathbf{1 . 2 \%}$ & $\mathbf{7 2 . 8 \%}$ & $\mathbf{2 5 . 0 \%}$ & $\mathbf{2 . 2 \%}$ & $\mathbf{6 9 . 4 \%}$ & $\mathbf{2 8 . 9 \%}$ & $\mathbf{1 . 7 \%}$ \\
\hline
\end{tabular}


Table 3. Body Mass Index by age groups \& gender in both, urban and rural areas of Albania

\begin{tabular}{|c|c|c|c|c|c|c|c|c|c|}
\hline \multirow{4}{*}{ Age } & \multicolumn{9}{|c|}{ TOTAL } \\
\hline & \multicolumn{3}{|c|}{ BOY } & \multicolumn{3}{|c|}{ GIRL } & \multicolumn{3}{|c|}{ TOTAL } \\
\hline & $\begin{array}{c}\text { UNDER } \\
\text { WEIGHT }\end{array}$ & NORMAL & OBESE & $\begin{array}{c}\text { UNDER } \\
\text { WEIGHT }\end{array}$ & NORMAL & OBESE & $\begin{array}{c}\text { UNDER } \\
\text { WEIGHT }\end{array}$ & NORMAL & OBESE \\
\hline & $\begin{array}{l}\text { Row } \\
\text { N \% } \\
\end{array}$ & $\begin{array}{l}\text { Row } \\
\text { N \% } \\
\end{array}$ & $\begin{array}{l}\text { Row } \\
\text { N \% } \\
\end{array}$ & $\begin{array}{l}\text { Row } \\
\text { N \% } \\
\end{array}$ & $\begin{array}{l}\text { Row } \\
\text { N \% } \\
\end{array}$ & $\begin{array}{l}\text { Row } \\
\text { N \% } \\
\end{array}$ & $\begin{array}{l}\text { Row } \\
\text { N \% } \\
\end{array}$ & $\begin{array}{l}\text { Row } \\
\text { N \% } \\
\end{array}$ & $\begin{array}{l}\text { Row } \\
\text { N \% } \\
\end{array}$ \\
\hline 10.00 & $71.4 \%$ & $25.0 \%$ & $3.6 \%$ & $62.0 \%$ & $31.5 \%$ & $6.5 \%$ & $66.8 \%$ & $28.2 \%$ & $5.0 \%$ \\
\hline \begin{tabular}{|l|}
11.00 \\
\end{tabular} & $63.9 \%$ & $34.0 \%$ & $2.1 \%$ & $68.3 \%$ & $31.0 \%$ & $.8 \%$ & $65.9 \%$ & $32.6 \%$ & $1.5 \%$ \\
\hline \begin{tabular}{|l|}
12.00 \\
\end{tabular} & $60.9 \%$ & $35.6 \%$ & $3.4 \%$ & $78.1 \%$ & $18.8 \%$ & $3.1 \%$ & $68.2 \%$ & $28.5 \%$ & $3.3 \%$ \\
\hline Total & $65.6 \%$ & $31.5 \%$ & $2.9 \%$ & $68.1 \%$ & $28.5 \%$ & $3.4 \%$ & $66.8 \%$ & $30.1 \%$ & $3.1 \%$ \\
\hline
\end{tabular}

Table 4. Eurofit test results of primary and secondary school students

in rural and urban areas of Albania

\begin{tabular}{|c|c|c|c|c|c|c|}
\hline \multirow{2}{*}{ Variables } & \multicolumn{3}{|c|}{ Urban Areas } & \multicolumn{3}{c|}{ Rural Areas } \\
\cline { 2 - 7 } & Age 10 & Age 11 & Age 12 & Age 10 & Age 11 & Age 12 \\
\cline { 2 - 7 } & $\mathbf{n = 1 2 5}$ & $\mathbf{n = 1 5 4}$ & $\mathbf{n = 6 1}$ & $\mathbf{n = 9 5}$ & $\mathbf{n = 1 1 6}$ & $\mathbf{n = 9 0}$ \\
\cline { 2 - 7 } & $\mathbf{X + - S D}$ & $\mathbf{X}+-$-SD & X+-SD & X+-SD & X+-SD & X+-SD \\
\hline Height (cm) & $145.84+-6.9$ & $149.64+7.5$ & $153.6+6.36$ & $145.40+-7.9$ & $147.15+-9.9$ & $152.54+-7.9$ \\
\hline Weight (kg) & $42.09+-10.2$ & $43.91+10.2$ & $46.64+-10.51$ & $37.16+-7.6$ & $39.35+-10.67$ & $42.28+-8.9$ \\
\hline BMI (\%) & $17.84+-3.8$ & $17.40+-3.9$ & $18.23+-3.75$ & $17.14+-2.9$ & $17.21+-3.15$ & $16.62+-3.7$ \\
\hline $\begin{array}{c}\text { Sit-Up abdominals } \\
\text { (30 s/times) }\end{array}$ & $8.53+-3.7$ & $8.80+-5.4$ & $9.97+-4.97$ & $13.99+-5.3$ & $13.89+-5.16$ & $13.78+-5.7$ \\
\hline Pull-Up (30 s/times) & $5.58+-3.5$ & $6.36+-4.4$ & $8.93+-5.54$ & $13.04+-6.1$ & $14.16+-7.04$ & $13.46+-7.3$ \\
\hline Sit and Reach (cm) & $8.55+-6.9$ & $9.78+-9.0$ & $8.75+-8.60$ & $14.69+-7.5$ & $12.98+-7.46$ & $14.08+-6.12$ \\
\hline 30m sprint (s) & $6.24+-0.62$ & $6.22+-0.54$ & $6.03+-0.52$ & $5.81+-0.40$ & $5.75+-0.38$ & $5.81+-0.42$ \\
\hline Shuttle run 112 m (s) & $23.49+-2.34$ & $23.28+-2.0$ & $22.83+-2.46$ & $22.02+-1.8$ & $21.84+-1.60$ & $22.10+-1.68$ \\
\hline Vertical Jump (cm) & $20.92+-6.05$ & $21.40+-5.4$ & $22.08+-5.90$ & $23.17+-6.8$ & $22.10+-1.68$ & $25.54+-4.37$ \\
\hline $\begin{array}{c}\text { Standing long jump } \\
\text { (cm) }\end{array}$ & $135.17+15.6$ & $134.83+17.3$ & $139.46+-18.25$ & $147.92+-14.7$ & $149.85+-15.4$ & $147.68+-17.7$ \\
\hline
\end{tabular}

Table 5. Eurofit test results of primary and secondary school students in rural and urban areas of Albania

\begin{tabular}{|c|c|c|c|}
\hline \multirow{2}{*}{ Variables } & Age 10 & Age 11 & Age 12 \\
\cline { 2 - 4 } & $\mathbf{n = 2 2 0}$ & $\mathbf{n}=\mathbf{2 7 0}$ & $\mathbf{n}=\mathbf{1 5 1}$ \\
\cline { 2 - 4 } & $\mathbf{X + - S D}$ & $\mathbf{X}+-$ SD & X+-SD \\
\hline Height (cm) & $145.65+-7.3$ & $148.57+-8.7$ & $152.97+-7.3$ \\
\hline Weight (kg) & $39.96+-9.4$ & $41.96+-10.6$ & $44.04+-9.8$ \\
\hline BMI (\%) & $17.53+-3.5$ & $17.31+-3.6$ & $17.27+-3.8$ \\
\hline $\begin{array}{c}\text { Sit-Up-abdominals } \\
\text { (30 s/times) }\end{array}$ & $10.89+-5.2$ & $10.99+-5.9$ & $12.24+-5.7$ \\
\hline Pull-Up (30 s/times) & $8.80+-6.1$ & $9.71+-6.9$ & $11.62+-7$ \\
\hline Sit and Reach (cm) & $11.20+-7.7$ & $11.16+-8.5$ & $11.93+-7.7$ \\
\hline 30m sprint & $6.05+-0.58$ & $6.02+-0.53$ & $5.90+-0.48$ \\
\hline Shuttle run 112 m & $22.86+-2.3$ & $22.66+-2$ & $22.39+-2.1$ \\
\hline Vertical Jump (cm) & $21.89+-6.5$ & $22.98+-5.7$ & $24.15+-5.3$ \\
\hline Standing long jump $\mathbf{( c m )}$ & $140.67+-16.5$ & $141.29+-18.1$ & $144.36+-18.3$ \\
\hline
\end{tabular}

\section{DISCUSSION}

Behaviors and traits of today's children, along with their genetics, are determinants of their growth and development; their physical, mental, and psy- chosocial health; and their physical, cognitive, and academic performance. Technological advances of modern society have contributed to a sedentary lifestyle that has changed the phenotype of children 
from that of 20 years ago. Children today weigh more and have a higher body mass index (BMI) than their peers of just a generation before (Ogden, Carroll, Kit, Flegal, 2012). This lack of participation in physical activity has contributed to a greater prevalence of pediatric obesity, a decrease in fitness levels (e.g., flexibility, muscular strength, cardiorespiratory capacity) and a greater risk for diseases (Mirwald, Bailey, 1986).

The sampling for this research consisted of 641 students, of which 298 were females and 108 were 10 years of age, 126 were 11 years of age and 64 were 12 years of age. The remaining 343 were males, and of the total number of males 120 were 10 years of age, 114 were 11 years of age and 87 were 12 years of age. Based on the BMI data, $4.4 \%$ of the sampled students in urban area are obese, $31.2 \%$ have an average weight, $64.4 \%$ are under weight. In rural areas, the obesity level is lower than in urban areas with $1.7 \%$ obese students, $28.9 \%$ of Behaviors and traits of today's children, along with their genetics, are determinants of their growth and development; their physical, mental, and psychosocial health; and their physical, cognitive, and academic performance. Technological advances of modern society have contributed to a sedentary lifestyle that has changed the phenotype of children from that of 20 years ago. Children today weigh more and have a higher body mass index (BMI) than their peers of just a generation before (Ogden, Carroll, Kit, Flegal KM, 2012). This lack of participation in physical activity has contributed to a greater prevalence of pediatric obesity, a decrease in fitness levels (e.g., flexibility, muscular strength, cardiorespiratory capacity) and a greater risk for diseases (Boreham, Riddoch, 2001).

The sampling for this research consisted of 641 students, of which 298 were females and 108 were 10 years of age, 126 were 11 years of age and 64 were 12 years of age. The remaining 343 were males, and of the total number of males 120 were 10 years of age, 114 were 11 years of age and 87 were 12 years of age. Based on the BMI data, $4.4 \%$ of the sampled students in urban area are obese, $31.2 \%$ have an average weight, $64.4 \%$ are under weight. In rural areas, the obesity level is lower than in urban areas with $1.7 \%$ obese students, $28.9 \%$ of average weight and $69.4 \%$ underweight. These figures show differences between the students of respective areas, but there is no considerable difference among opposite sexes in both rural and urban areas. Based on the BMI data, it results that out of the total share of students, $6.5 \%$ females and $3.6 \%$ males aged 10 , $8 \%$ females and $2.1 \%$ males aged $11,3.1 \%$ females and $3.4 \%$ males aged 12 range from overweight to obese. The overall BMI assessment shows that the total share of students who range from overweight to obese is $3.1 \%$, where $2.9 \%$ of males are overweight or obese and $3.1 \%$ of females are overweight or obese. These figures show that although physical activity is inversely related to weight, correlations are generally low $(\sim \mathrm{r}-0.15)$, and differences in body weight between active and inactive boys and girls tend to be small (Mirwald, Bailey, 1986). The Eurofit test data show differences in students of different ages, but what matters most are the differences between students in rural and urban areas in terms of motor development in all the components of the test. This is an important result not only in the preparation of students, but also serves as an indicator to identify sports talents by supporting them and orienting them towards sports that are most suitable for them based on their specifics. An important question arises from the figures: Is there any state mechanism to support and assist the talents who live in rural areas and who could be a potential for the sports development in Albania? This must be a priority concern of the Albanian government to support morally and financially talented students in rural areas while acknowledging the fact that poverty is a concept which is expressed quantitatively in the per capita income indicators and in the capacity of individuals to meet the basic living expenses. One should bear in mind also the fact that the majority of people in rural areas live in absolute poverty despite the narrowing contrast, throughout the years with urban areas.

\section{REFERENCES}

Adam, C., Klissouras, V., Ravazzolo, M., Renson, R., Tuxworth, W., (1988) "Eurofit: European Test of Physical Fitness" Council of European Committee for Development of Sport, Rome.

Boreham, C., Riddoch, C., (2001). The physical activity, fitness and health of children, Journal of Sports Sciences, 19 (12), pp. 915-929.

Denkere, M., Andersen, LB. (2008). Health-related aspects of objectively measured daily physical activity in children. Journal of Sports Medicine, pp. 28; pp.133-144. Fernández, C., Glaister, M., Lockey, R., (2015). The validity and reliability of an iPhone app for measuring vertical jump performance, Journal of Sports Sciences, 
33(15):15741579.

Gallahue, DL. (1982). Developmental Movement Experiences for Children, New York: Collier Macmillan.

Mirwald, R., Bailey, D. (1986). Maximal aerobic power, London, Ontario, Sports Dynamics.

Ogden, C.L., Carroll, M.D., Kit, B.K., Flegal, K.M., (2012). Prevalence of obesity and trends in body mass index among U.S. children and adolescents 1999-2010, Journal of the American Medical Association, 307(5), pp. 483-490.

Testing physical fitness - EUROFIT experimental bat- tery: provisional handbook. (1983). Council of Europe, Strasbourg.

Tomkinson, G.R, Olds, T.S., Borms, J. (2007). Who are the Eurofit test? Medicine and Sport Science, pp. 50, pp.104-128.

\section{Corresponding author:}

Rovena Elmazi

Activity and Recreation Sports University of Tirana, Faculty of Physical, Albania E-mail: rd.elmazi@gmail.com 